Journal of Animal and Veterinary Advances 11 (11): 1897-1900, 2012

ISSN: $1680-5593$

(C) Medwell Journals, 2012

\title{
Development of a Reverse Transcription Loop-Mediated Isothermal Amplification Assay for Visual Detection of Porcine Epidemic Diarrhea Virus
}

\author{
${ }^{1}$ Sun Quan-Wen, ${ }^{1}$ Wu Shu-Qin, ${ }^{1}$ Yang Cui-Jun, ${ }^{2}$ Wang Jin-Liang, \\ ${ }^{1} \mathrm{Ge}$ Jian, ${ }^{1} \mathrm{Chang}$ Bao and ${ }^{1} \mathrm{Xu}$ Tong \\ ${ }^{1}$ Hebei North University, 075000 Zhangjiakou, China \\ ${ }^{2}$ Binzhou Academy of Shandong, \\ Institute of Animal Science and Veterinary Medicine, 256600 Binzhou, China
}

\begin{abstract}
To develop a new, rapid, practical and sensitive method for detection of Porcine Epidemic Diarrhea Virus (PEDV), a Reverse Transcription Loop Mediated isothermal Amplification (RT-LAMP) assay was established based on six primers in the conserved gene. The method had specificity but no cross-reaction with other viruses and was 100 fold higher than RT-PCR. The result suggested that the newly developed RT-LAMP assay is a simple and specific method for rapid detection of PEDV in field conditions and it has a high practical value in PEDV integrated control and early diagnosis.
\end{abstract}

Key words: PEDV, LAMP, detection methods, diagnosis, virus, China

\section{INTRODUCTION}

Porcine Epidemic Diarrhea (PED) which is diseased by Porcine Epidemic Diarrhea Virus (PEDV) is a highly contagious, enteric disease of swine characterized by vomiting, dehydration and a high mortality in piglets. PED has relatively high morbidity and mortality rates in piglets, fattening pigs and store pigs, especially in piglets (Chae et al., 2000) and had been brought large economy losses to the pig industry all over the world. There were many detection methods (Kim and Chae, 2001, 2002; Jung et al., 2003; Kim et al., 2000) which include clinical observation, microscopic observation, neutralization test, immunofluorescence technique, Enzyme-Linked Immunosorbent Assay (ELISA), immunohistochemical technique, in situ hybridization and polymerase chain reaction. However, now there is no rapid method in the detection of large-scale clinical samples. In this study, the method of LAMP which is a rapid and practical method would be set up. This method could detect small sample of PEDV and realize the early and rapidly virus detection.

\section{MATERIALS AND METHODS}

Virus strain: Porcine Epidemic Diarrhea Virus (PEDV), Transmissible Gastroenteritis Virus (TGEV), Porcine Rotavirus (PRV), Porcine Reproductive and Respiratory Syndrome Virus (PRRSV) and Swine Fever Virus (CSFV) were provided by the laboratory and stored.
Treatment of diseased: Small intestine and its contents of pathological pigs were added to DMEM which contains $3 \%$ newborn calf serum at a ratio of $1-5$. The mixtures were transferred into a centrifuge tube of $1.5 \mathrm{~mL}$ and then the mixtures were repeatedly frozen and thawed in three times. The mixtures were centrifuged at $5000 \mathrm{r} \mathrm{min}^{-1}$ for $10 \mathrm{~min}$ in follow. Supernatants were collected.

Reagents Betaine was purchased from Sigma, 1000X fluorescent dye SYBR Green 1 were purchased from Invitrogen Corporation. rTaq DNA polymerase $\left(5 \mathrm{U}_{\mu} \mathrm{L}^{-1}\right)$, dNTP, DNA Marker DL2000 from Takara Bio Co., Ltd. BstDNA polymerase from New England Biolabs Inc., USA, Inc.; trypsin, DMEM from Gibco-BRL, Inc. others from Sangon Shanghai biotech (Shanghai) Co., Ltd.

The primers of RT-LAMP: According to the conserved sequence of $N$ gene in PEDV primers were designed by primer explorer V4 Software. The primers included a pair of outer primers F3 and B3, a pair of inner primers FIP and BIP, a pair of PCR primers that amplified fragment size of 177 bp. All primers were synthesized by Sangon Shanghai biotech (Shanghai) Co., Ltd. The sequences of primer are as follows:

BIP: 5'-GCAGCTTGCTTCGGACCCAGTTTTCCTGACGC ATCAACACCTT-3'

FIP: 5'-CGCCCTTGGGAATTCTCCTCCTTTTGGCCACT

CGAAGGAACG-3'

B3: 5'-AACTGGCGATCTGAGCATAG-3'

F3: 5'-ACAGCGGCAAAAATACACCT-3'

Corresponding Author: Wu Shu-Qin, Hebei North University, 075000 Zhangjiakou, China 
P1: 5'- GGAACAGGACCTCACGCC -3'

P2: 5'-AGGTTCAACAATCTCAACTACACTG -3'

The extraction of viral RNA: About $250 \mu \mathrm{L}$ virus solution was added to $500 \mu \mathrm{L}$ Trizol, oscillated $1 \mathrm{~min}$, room temperature for $10 \mathrm{~min}$. About $200 \mu \mathrm{L}$ chloroform was added and mixed thoroughly, room temperature for $10 \mathrm{~min}$ then centrifuged at $12000 \mathrm{r} \mathrm{min}^{-1}$ for $10 \mathrm{~min}$ at $4^{\circ} \mathrm{C}$. The supernatant was transferred to a new $1.5 \mathrm{~mL}$ tube to which one time isopropyl alcohol was added and mixed thoroughly, precipitated at $-20^{\circ} \mathrm{C}$ for $50 \mathrm{~min}$, centrifuged at $12000 \mathrm{r} \mathrm{min}^{-1}$ for $10 \mathrm{~min}$, dissolved the precipitation with $20 \mu \mathrm{L}$ of DEPC-treated water.

The RT-LAMP reaction conditions determined of PEDV: The LAMP reaction system of PEDV was $25 \mu \mathrm{L}: 10 \mathrm{X}$ buffer for $2.5 \mu \mathrm{L}$, AMV $\left(5 \mathrm{U}_{\mu} \mathrm{L}^{-1}\right)$ for $1.0 \mu \mathrm{L}$, Bst $\mathrm{E}$ $\left(8 \mathrm{U}_{\mu} \mathrm{L}^{-1}\right)$ for $1.0 \mu \mathrm{L}, \mathrm{dNTP}(2.5 \mathrm{mM})$ for $4 \mu \mathrm{L}$, the primers of FIP and BIP $(40 \mu \mathrm{M})$ for $0.5 \mu \mathrm{L}$, the primers of $\mathrm{F} 3$ and B3 $(15 \mu \mathrm{M})$ for $0.5 \mu \mathrm{L}$, template for $4.0 \mu \mathrm{L}, 5 \mathrm{M}$ betaine for $5.0 \mu \mathrm{L}$ and $5.5 \mu \mathrm{L}$ of water. The LAMP reaction solutions were respectively incubated at water bath of $63^{\circ} \mathrm{C}$ for 30 , 45,60 and $120 \mathrm{~min}, 10 \mu \mathrm{L}$ of reaction products were analysised with $2 \%$ agarose gel.

The visual detection of PEDV by RT-LAMP: After the end of reaction, $1 \mu \mathrm{L}$ dye SYBR Green was added to the LAMP reaction solutions, observing the color of the LAMP reaction solution and then whether reaction solution produced fluorescence in UV light.

Sensitivity and specificity detection of PEDV by RTLAMP: The plasmid of pMD18-N which contians $N$ gene of PEDV was diluted into six concentrations, there respectively contained $1 \times 10^{5}, 1 \times 10^{4}, 1 \times 10^{3}, 1 \times 10^{2}, 1 \times 10^{1}$ and $1 \times 10^{\circ}$ plasmid copies per microliter, $1 \mu \mathrm{L}$ solution were used to RT-LAMP and PCR testing and tissue RNA was extracted from the pig which carried PEDV, TGEV, PRV, PRRSV and CSFV. Healthy pigs were the negative control. All templates were used to RT-LAMP to verify the specificity of the method.

Repeatability detection of PEDV by RT-LAMP: Three different people who detected the PEDV three times with time intervale of 5 and 10 days, detected 20 of PEDV that collected from different cell culture passages. Coefficients of variation were calculated base on the test result of RT-LAMP.

RT-LAMP detect PEDV on clinical: The RNA extracted from 12 material of porcine epidemic diarrhea was detected by RT-PCR and RT-LAMP.

\section{RESULTS}

PEDV RT-LAMP reaction system optimized: The LAMP reaction solutions were reacted after $30,45,60$ and $120 \mathrm{~min}$ then the reaction products were analysised with agarose gel, the result showing that after amplified 45, 60 and $120 \mathrm{~min}$ there were specific bands but after amplified $30 \mathrm{~min}$ there were no bands (Fig. 1).

The visual effect of PEDV by RT-LAMP: From the result researchers could see, after amplified 45,60 and $120 \mathrm{~min}$, dye SYBR Green was added to the LAMP reaction solutions, the reaction solutions showed a clear emerald green. But after amplified $30 \mathrm{~min}$, dye SYBR Green was added, the reaction solution was pale orange (Fig. 2).

Sensitivity effects of PEDV by RT-LAMP: Total RNA whose Concentration was $5.6 \mathrm{ng} \mu \mathrm{L}^{-1}$ were extracted from $250 \mu \mathrm{L}$ virus solution, 10 fold gradient dilution of total RNA were as a template for RT-LAMP and PCR. The result showed that the RNA sensitivity concentrations of PEDV that were measured by the method of LAMP were $5.6 \times 10^{-6}$ ng $\mu \mathrm{L}^{-1}$ (Fig. 3) and The RNA sensitivity concentrations of PEDV that were measured by PCR were $5.6 \times 10^{-3}$ ng $\mu \mathrm{L}^{-1}$ (Fig. 4).

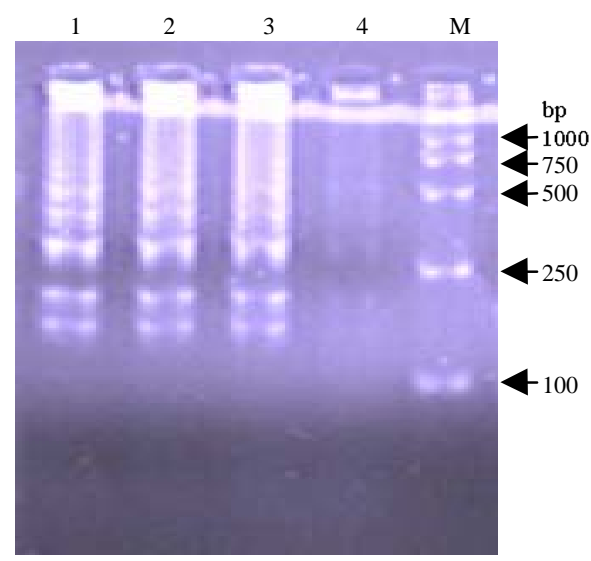

Fig. 1: PEDV RT-LAMP reaction system optimized; 1 : 120; 2: 60; 3: 45 and 4: 30 min; M: DL2000 Marker

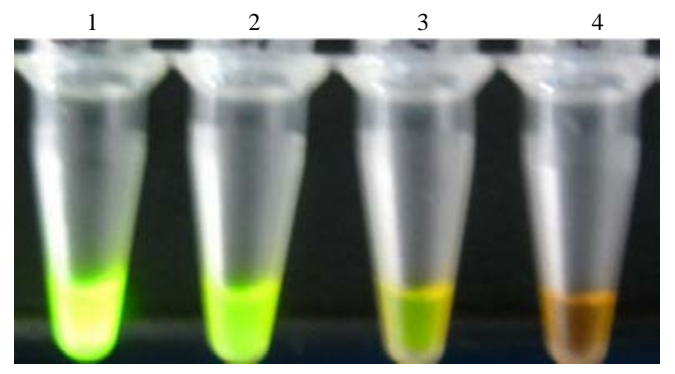

Fig. 2: The visual effect of PEDV by RT-LAM; 1: 120, 2: 60, 3: 45 and 4: $30 \mathrm{~min}$ 


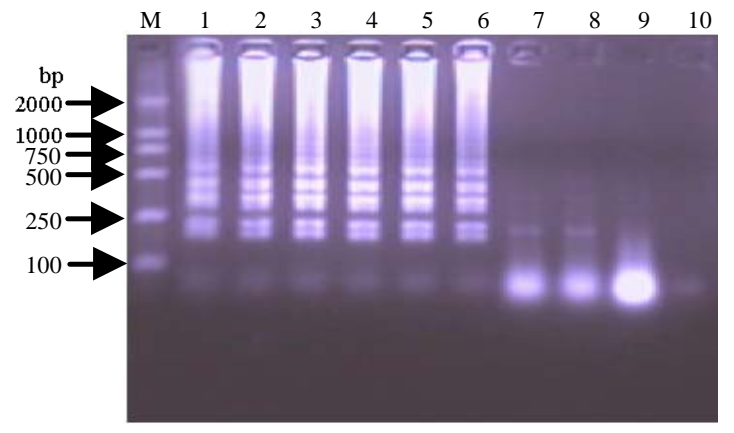

Fig. 3: Sensitivity effects of PEDV by RT-LAMP; M: DL2000Marker; 1-10: 10 fold gradient dilution of total RNA of PEDV $\left(5.6 \times 10^{-1}\right.$ to $\left.5.6 \times 10^{-10} \mathrm{ng} \mu \mathrm{L}^{-1}\right)$ were the template of RT-LAMP

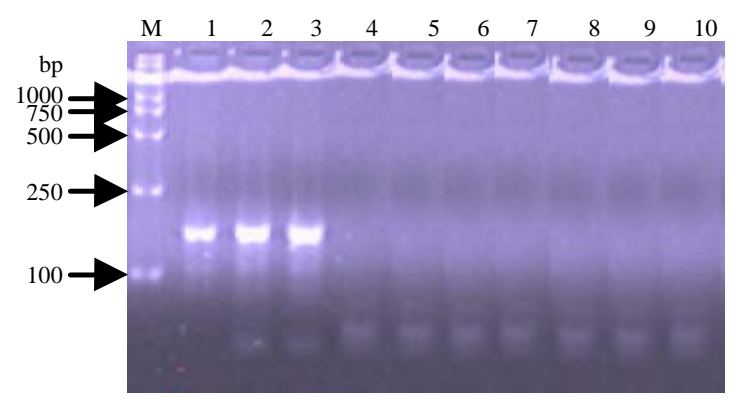

Fig. 4: Sensitivity effects of PEDV by RT-PCR; M: DL2000 Marker; 1-10: 10 fold gradient dilution of total RNA of PEDV $\left(5.6 \times 10^{-1}\right.$ to $\left.5.6 \times 10^{-10} \mathrm{ng} \mu \mathrm{L}^{-1}\right)$ was the template of RT-PCR

Specificity effects of PEDV by RT-LAMP: The method of LAMP on PEDV can detect the nucleic acid of PEDV. However, this method could not detect the nucleic acids of TGEV, PRV, PRRSV and CSFV even the isothermal amplification time was extended to $2 \mathrm{~h}$. The total RNA of healthy animal tissue and sterile water were the negative control (Fig. 5).

Repeatability effects of PEDV by RT-LAMP: About 20 different cell culture passages of PEDV were detected by RT-LAMP, intra-assay coefficient of variability were 5.3 , 3.1 and $3.0 \%$, respectively and inter-assay coefficient of variability were $3.4 \%$. This result showed that the method has good repeatability (Table 1 ).

RT-LAMP applying on clinical on PEDV: About 12 suspected diseased were extracted total RNA and detected by RT-LAMP, those RNA detected by RT-PCR, the positive rate of PEDV in samples was $58.3 \%$ (8/12). This result showed, the detection sensitivity of RT-LAMP was higher than conventional RT-PCR (Table 2).

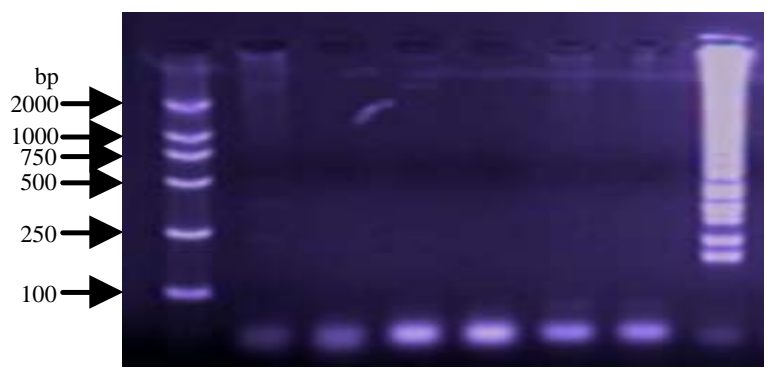

Fig. 5: Electrophoresis results of RT-LAMP on PEDV; M: DL2000 Marker; 1-7: Electrophoresis results of RT-LAMP, respectively was the total RNA of TGEV, PRV, PRRSV, CSFV, healthy animal tissue, $\mathrm{H}_{2} \mathrm{O}$ and $\mathrm{PEDV}$

Table 1: Repeatability effects of PEDV by RT-LAMP

\begin{tabular}{lccc}
\hline & & Coefficient of variability (CV (\%)) \\
\cline { 3 - 4 } Batch & Number of positive (A) & Intra-assay & Inter-assay \\
\hline 1 & 20 & 5.3 & 3.4 \\
& 18 & - & - \\
2 & 19 & - & - \\
& 19 & 3.1 & - \\
3 & 18 & - & - \\
& 18 & - & - \\
& 19 & - & - \\
\hline
\end{tabular}

Table 2: The comparison of RT-LAMP and RT-PCR on clinical on PEDV Sample

\begin{tabular}{lcccccccccccc} 
number & 1 & 2 & 3 & 4 & 5 & 6 & 7 & 8 & 9 & 10 & 11 & 12 \\
\hline RT-PCR & + & - & + & + & - & + & - & - & + & - & + & +
\end{tabular}

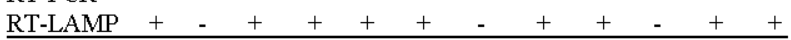

+: Positive result; -: Negative result

\section{DISCUSSION}

In the 1980 s, the first PEDV was found in China and since then many reports have been published about PED. In recent years, the disease is showing a gradually expanding trend. Therefore, an effective method which is a rapid and accurate detection for PDE in early time has a great significance (Sun et al., 2006). A novel isothermal method of nucleic acid amplification known as LoopMediated isothermal Amplification (LAMP) proposed by Notomi has been developed. The technology relied on the six primers which was specific areas in the target sequence could be identified and the BstDNA polymerase which had the function of unwinding, target sequences could be efficient, rapid, specific amplification at a constant temperature.

\section{CONCLUSION}

In this study, The LAMP Method employs four primers that specifically recognize six distinct sequences 
on the target DNA and a Bst polymerase that has a strand displacement activity, four primers including Forward Inner Primer (FIP), Forward outer primer (F3), Backward Inner Primer (BIP), Backward outer primer (B3). The target DNA can be amplified from a few original copies to $109 \sim 1010$ copies in $<1 \mathrm{~h}$ under isothermal conditions ranging from $60-65^{\circ} \mathrm{C}$. To compare the sensitivity of LAMP and PCR for detecting the PED, the sensitivity of LAMP was $5.6 \times 10^{-6} \mathrm{ng} \mu \mathrm{L}^{-1}$ and the sensitivity of PCR was $5.6 \times 10^{-3} \mathrm{ng} \mu \mathrm{L}^{-1}$ so, LAMP had strong sensitivity and very high, specificity. If dye SYBR Green is added to the LAMP reaction solutions, the result can be judged through eyes (Tsugunori et al., 2000; Zhi-Feng et al., 2008). The step of LAMP is very easy. This method could greatly improve the efficiency of detection and could apply on base and site. In this study, LAMP technology applied on the detection of PEDV in order to study the sensitivity specificity, repeatability and stability of LAMP. It proved that this method has the advantage of simple, rapid, sensitive and specific, etc. so, it has very high practical value on comprehensive prevention and early diagnosis of PEDV.

\section{ACKNOWLEDGEMENT}

This study was supported by the Natural Science Foundation of Hebei province (C2009001028).

\section{REFERENCES}

Chae, C., O. Kim, C. Choi, K. Min, W.S. Cho, J. Kim and J.H. Tai, 2000. Prevalence of porcine epidemic diarrhea virus and transmissible gastroenteritisvirus infection in Korean pigs. Vet. Rec., 147: 606-608.
Jung, K., J. Kim, O. Kim, B. Kim and C. Chae, 2003. Differrentiation between porcine epidemic diarrhea virus and transmissible gas-troenteritis virus in formalin-fixed parafinembedded tissues by multiplex RT-nes-ted PCR and comparison with in situ hybridization. J. Virol. Methods., 108: 41-47.

Kim, B. and C. Chae, 2001. In situ hybridization for the detection of trans missible gastroenteritis virus in pigs and comparison with other methods. Can. J. Vet. Res., 65: 33-37.

$\mathrm{Kim}, \mathrm{O}$. and C. Chae, 2002. Comparison of reverse transcription polymerase chain reaction, immunobistochemistry and in situ hybridization for the detection of porcine epidemic diarrhea virus in pigs. Can. J. Vet. Res., 66: 112-116.

Kim, O., C. Choi, B. Kim and C. Chae, 2000. Detection and differentiation of porcine epidemic diarrhoea virus and transmissible gastroenteritis virus in clinical samples by multiplex RT-PCR. Vet. Rec., 146: $637-640$.

Sun, D.B., L. Feng, H.Y. Shi and J.F. Chen, 2006. Progress on molecular biology of porcine epidemic diarrhea virus. Prog. Vet. Med., 27: 11-14.

Tsugunori, N., H. Okayama, H. Masubuchil, T. Yonekawa, K. Watanabe, N. Amino and T. Hase, 2000. Loop-mediated isothermal amplification of DNA. Nucl. Acids Res., 28: 1-63.

Zhi-Feng, Q., C. Shao-Ling and R. Zhou-Xi, 2008. Development of a novel RT-LAMP assay for foot-and-mouth disease virus. Chin. J. Preventive Vet. Med., 30: 375-378. 